\title{
Lisandro Rodríguez. Yerba mate y cooperativismo en la Argentina. Sujetos sociales y acción colectiva en el NEA (1936-2002). Universidad Nacional de Quilmes, Bernal, 2018, 240 pp.
}

\author{
Rocío Soledad Poggetti \\ Centro de Investigaciones Históricas-Universidad Nacional de Río Cuarto, \\ Centro de Investigaciones Históricas de la Facultad de Filosofía y Humanidades, \\ Universidad Nacional de Córdoba.CONICET, Argentina \\ rociopoggetti@hotmail.com
}

La historia económica del Noreste Argentino (NEA) y particularmente de la cuenca yerbatera (Misiones y noroeste de Corrientes) ha constituido una temática secundaria en la historiografía argentina del siglo XX. A fines del mismo y particularmente en el siglo XXI, se intensificó la preocupación por indagar la dinámica regional, evaluando los aportes que realizan las cooperativas para fortalecer los procesos de acción colectiva en el agro y su contribución al sostenimiento de la agricultura familiar, base de la economía yerbatera.

En este marco, el libro de Lisandro Rodríguez constituye un aporte central al debate en tanto que, desde una perspectiva histórica, ${ }^{1}$ contribuye a profundizar el conocimiento sobre el desarrollo de una "región económica marginal", a comprender las transformaciones de las cooperativas yerbateras en función de las cambiantes condiciones impuestas por los regímenes sociales de acumulación y a problematizar el impacto socioeconómico de las cooperativas. El eje del análisis se sienta en las conflictivas relaciones entre empresas industrializadoras y comercializadoras por un lado y productores y cooperativas por otro, en un sólido intento por cuenta de la trama de intereses, los conflictos y las resistencias que se producen en una actividad profundamente regulada por el Estado durante el siglo XX.

El libro se encuentra organizado en seis capítulos. En el primero, el autor historiza la región tomando como eje la intervención del Estado Nacional en el cultivo de la yerba mate. En este sentido, introduce el papel de este como difusor del cultivo industrial de la yerba desde la década de $1920{ }^{2}$ La colonización oficial en tierras fiscales fomentó el desarrollo del colono y contribuyó a organizar una estructura social agraria en la que predominaba la pequeña propiedad. Se consolidó así una economía familiar especializada en la producción de yerba en el marco de una trama productiva concentrada. Fue la crítica situación que vivía al agro desde 1930 -causada por la sobreproducción y la importación de yerba mate desde Brasil y Paraguay- lo que motivó la creación de dos instituciones: la Comisión Reguladora de la Yerba Mate (CRYM) en 1935-que en 1950 pasó a llamarse Comisión Nacional de la Yerba Mate (CNYM) - como ente controlador de la producción a través del establecimiento de cupos y limitaciones, y el Mercado Concentrador en 1936, que centralizaba la compraventa del producto. A través de acciones concretas, como la disminución de impuestos y la facilidad crediticia, ambas fomentaron el accionar cooperativo; estas iniciaron así una progresiva inserción en el entramado productivo y asociativo regional, vinculando principalmente a pequeños y medianos productores. 
En el segundo capítulo realiza una descripción de la evolución cualitativa y cuantitativa del cooperativismo agropecuario en relación a las cambiantes condiciones impuestas por los regímenes sociales de acumulación. Tras definirlas como organizaciones "sui géneris", analiza su función como reductoras de la intermediación comercial y evalúa los aportes que realizan a los socios a partir de las estrategias de acción colectiva. Desde la década de 1920 la producción yerbatera inició un proceso de desarrollo sostenido, el cual continuó con la expansión de los cultivos industriales en el marco del régimen social de acumulación sustitutivo (1930-1990). Se favoreció en este momento un "modelo institucional consecuente", en el que la fricción entre los objetivos sociales y los económicos se reducían a su mínima expresión. A partir del derrocamiento de Perón se inició un período de estancamiento, e incluso de retroceso del movimiento cooperativo. ${ }^{3} \mathrm{El}$ régimen social de acumulación neoliberal (1990-2001), en el que desaparecieron un amplio porcentaje de productores y cooperativas, fomentó las “organizaciones institucionales en mutación”. En ese contexto, la opción empresarial fue evaluada por ciertas asociaciones como una adecuación necesaria de la estructura organizativa para vincularse exitosamente al mercado.

En el tercer capítulo profundiza el desarrollo de la industria yerbatera desde la década de 1920 en relación a los conflictos entre los diversos actores y la intervención del Estado. En función a ello delinea dos etapas en la historia del movimiento cooperativo yerbatero: 1926-1946 y 1946-1955. En este sentido, la crisis de sobreproducción que se desató durante la década de 1930 impuso la necesidad del establecimiento de cupos y limitaciones a la cosecha por parte del Estado. En este marco de constante expansión de la superficie cultivada y de la colonización se reforzó el papel de las cooperativas, activas asociaciones que no sólo oficiaban como intermediarios para fortalecer el peso de los pequeños y medianos productores frente a los molineros sino también como agentes colonizadores e impulsores del acceso a la tierra. ${ }^{4}$ En el segundo período se abrió un espacio de diálogos entre el Estado y las cooperativas yerbateras, no exento de tensiones, que habilitó un crecimiento exponencial de las mismas. Ello se relacionó a las políticas favorables del peronismo, a la expansión de la colonización y al incremento de los cupos y los cultivos habilitados en la década de 1950. En este contexto, el objetivo de la CNRYM y del Mercado Consignatario fue sostener el precio pagado al colono para cubrir los costos de producción al tiempo que se proyectaba, en pos de reducir la concentración de la actividad y los costos de intermediación, la creación de plantas industriales en las zonas productoras. Propuesta resistida por los molineros, quienes ocupaban espacios de poder dentro del Estado. ${ }^{5}$

En el cuarto capítulo avanza temporalmente analizando la crisis que experimentó el agro regional en la década de 1960 y las estrategias de las cooperativas yerbateras en relación a los cambios en la política estatal. Frente a la crisis de sobreproducción el gobierno impuso nuevos cupos a la producción y prohibió el levantamiento de la cosecha de 1966, medida que se entiende en el marco de un fuerte proceso de concentración capitalista en el agro misionero. ${ }^{6}$ En contrapartida, la descapitalización de los colonos se acentúa de la mano del retraimiento del Estado en la intervención económica y el debilitamiento de los canales de acompañamiento financiero. Se fortaleció frente a este contexto el componente reivindicativo de las cooperativas, particularmente de la Federación de Cooperativas de Misiones (FEDECOOP). Sin embargo, atravesó un fuerte proceso de cuestionamiento por parte de los asociados debido a las alianzas que se tejieron con los grupos concentrados de poder ante los inminentes avances del mercado. En consecuencia, surgieron asociaciones no cooperativas que aglutinaban a los pequeños y medianos productores y esgrimían estrategias de acción colectiva, como los paros y las movilizaciones, acentuando la ya característica fragmentación en la representación de los intereses agrarios.

En el quinto capítulo, el autor estudia la crisis de la economía yerbatera y del cooperativismo a ella vinculada en el contexto de expansión del régimen social de acumulación neoliberal desde la década de 1990. La acentuación de la desregulación de la actividad y el retraimiento general del Estado puso en jaque un modelo productivo que evidenciaba serias dificultades desde la década de 1970. Por un lado, se agudizó la polarización del agro en tanto se debilitaron los pequeños y medianos productores que quedaron, así, a merced de los grupos concentrados de la economía como los complejos agroindustriales y las cadenas de hipermercados. 
Por otro, se transformó la estructura agraria del Noreste de la mano de la expansión de la industria forestal y la diversificación de la producción, asociado a la crisis generalizada de la producción yerbatera. A raíz de estos cambios se acentuó la conflictividad en el agro, sobre todo entre productores y sectores industriales, que fue canalizada por renovadas modalidades de resistencia y protesta, al tiempo que las antiguas cooperativas reestructuraron sus discursos y estrategias de acción. ${ }^{7}$

En el sexto y último capítulo propone, desde el nivel interno de las cooperativas, analizar cómo estas reestructuraron sus estrategias en función a la desigual penetración del capitalismo en el agro durante la década de 1990. Propone dos estudios de caso. La Cooperativa de Productores Yerbateros Jardín América nuclea a una base social de productores familiares pequeños y medianos con posibilidades de capitalización. La crisis financiera que atravesó la asociación, producto de la disminución de unidades productivas así como de la competencia de los molinos, la motivó a emprender la diversificación de los cultivos de los asociados, para lo cual ofició no sólo como agente de comercialización sino también como difusora de tecnología entre los mismos. Una trayectoria disímil siguió la Cooperativa Yerbatera de Andresito Ltda., creada en 1983 en el contexto de consolidación de la colonización en la región. A pesar de la crítica situación generalizada de la yerba mate a fines del siglo XX, sostuvo la especialización productiva de sus asociados, en parte debido a las posibilidades de reproducción de los mismos así como a la capacidad productiva de las plantaciones jóvenes.

En síntesis, el libro recorre las transformaciones económicas, productivas y asociativas de la región Noreste Argentina. Enfatiza en la producción yerbatera, el movimiento cooperativo, los conflictos entre los pequeños productores y los sectores industriales y comercializadores en relación a la intervención estatal durante el siglo XX. En este sentido, aporta a la profundización del conocimiento sobre la dinámica de una región poco estudiada y también enriquece significativamente a los estudios sobre el cooperativismo agrario en tanto permite reconocer, desde una polifonía de voces, las tensiones que atraviesan el desenvolvimiento de estas asociaciones. Finalmente, se constituye en un insumo clave para la gestión de políticas públicas que tiendan al apuntalamiento de la economía familiar y las cooperativas a ellas vinculadas, entendiendo que son estas el sostén histórico de la producción yerbatera.

\section{Notas}

1 Desde la metodología comparativa y el estudio de casos utiliza una diversidad de técnicas cualitativas y cuantitativas de recolección y análisis de datos que le permiten dar cuenta de las interrelaciones entre los distintos actores. $\mathrm{Al}$ mismo tiempo, realiza un análisis de interpretación a partir de categorías conceptuales.

2 Define a esta región como una de frontera, tanto política como económica, sobre la cual el Estado avanzó desde principios del siglo XX con un doble objetivo, la seguridad jurídica por un lado y el desarrollo económico por otro. Profundiza esta dimensión del análisis precisando categorías para comprender el proceso de expansión estatal sobre las fronteras, en un contexto de consolidación institucional del mismo así como de expansión económica. En este sentido, explica que las fronteras estatales artificiales se sobrepusieron sobre las históricas, gestadas en la relación entre las poblaciones de Argentina, Brasil y Uruguay. La acción colonizadora del Estado y de las empresas privadas, que se inició paralelamente a la oficial y fue desarrollada por empresarios que concentran los diversos eslabones del circuito productivo, contribuyó a la consolidación de una sociedad multiétnica que manifiesta profundas diversidades intraregionales.

3 A pesar de lo cual se produjo su afianzamiento institucional a través de la creación de CONINAGRO, en 1956, y de la sanción de la Ley 20.337 de 1973, cuyo principal objetivo fue adecuar el marco normativo al contexto.

4 La diversidad en la composición étnica, la zona en la que se asentaban los colonos, el origen oficial o privado de la colonización así como el tipo de vinculación establecida por el Estado, marcaron una multiplicidad de trayectorias asociativas. En este marco, describe brevemente el desarrollo institucional de la Cooperativa Agrícola Oberá, la Cooperativa de Yerba Mate de Santo Pipó (asociación líder en la producción de yerba mate a través de su marca propia "Piporé"), la Cooperativa Agrícola Eldorado SCL, la Cooperativa Agrícola Puerto Rico, la Cooperativa Agrícola Colonia Oro Verde Ltda., la Cooperativa Agrícola Ltda. de Puerto Victoria y la Federación de Cooperativas de Misiones Ltda. (FEDECOP). Destaca el origen de las mismas, la composición étnica mayoritaria de los colonos asociados así como las estrategias principales en relación a la producción, comercialización e industrialización -yerba mate principalmente, pero también tung, arroz, aceite de tung, tabaco y miel-. 
5 Es sintomático en este sentido el caso de la Cooperativa Agrícola Overá, que proyectó apoyado por el gobierno peronista la colonización agraria de la región de San Pedro, la cual se trunca ante el golpe de Estado de 1955.

6 En este sentido, esta medida no se acompaña de una prohibición de la importación en tanto que los intereses de la reciente burguesía agraria predominan en la CRYM.

7 En este sentido el autor reconoce a partir de estudios de caso aquellas que se plegaron a las prácticas empresariales para competir exitosamente en un mercado abierto y las que, vinculadas a los pequeños y medianos productores, sostuvieron prácticas de fortalecimiento productivo de sus asociados. 